\title{
Notas al casticismo de Rubén
}

H españa contemporánea, lo vemos impaciente ante quienes dicen; y
Juginas madrileñas de Rubén Darío, recogidas luego en su hasta escriben, prerrafaelista por prerrafaelita. ¿Será, para Rubén, un simple problema de sufijos? Nada simple. Interesa a uno, de los muy variados y vitales registros de su humor gramatical. El escritor desea estar al día, en lo que toca al arte y al pensamiento, y habla a quienes lo están, y se burla de aquéllos que con mala voluntad y peor información atacan a los modernistas acusándolos "de decadentes, de estetas, de prerrafaelistas, con $s$ y todo". "También por el hilo del sufijo equivocado se saca el ovillo de la incultura y de la aviesa intención. Es en ese mismo artículo donde, con parecido malhumor, afirma Rubén contra los adversarios de la nueva literatura: "Los que son tachados de simbolistas no tienen una sôla obra simbolista. A Valle-Inclán le llaman decadente porque escribe en una prosa trabajada y pulida, de admirable mérito formal".2 ¿Cuestiones de palabras? Sí, esenciales cuestiones de palabras. Eso es lo que importa en Rubén. No afán de gramatiquerías, pero sí una seria conciencia del idioma; inseparable, claro está, de su conciencia de la literatura (en el mejor sentido): un interés permanente y ramificado en muy diversos aspectos de la palabra, de los "peligrosos y delicados medios"'3 de que el poeta se sirve.

No será él quien admita que una lengua entre todas-su amada lengua francesa-sca la predestinada a la expresión infinitamente flexible de mínimas y raras sensaciones. ${ }^{4}$ Nada está prohibido de ante-

\footnotetext{
1. "El modernismo", en España contemporánea, Madrid, 1919(?), p. 269. Mortificante errata en Los Raros, Madrid, 1920, p. 192, a propósito de Dante Gabriel Rossetti: "exquisito prerrafaelista".

2 "El madernismo", p. 271.

3. "Dilucidaciones", de El canto errante, en Poesías completas, ed. A. Méndez Plancarte y A. Oliver Belmás, Madrid, 1967 (abreviaré: Poesías), p. 699.

4 Comp. José Entique Rodó, "Rubén Dario", en Obras completas, ed. E. Rodríguez Monegal, Madrid, 1957, pp. 176-177.
} 
mano a la lengua española: a la de los místicos, a la de Bécquer, a la de Martí, Gutiérrez Nájera y Silva. Rubén asiste, optimista y activo, al espectáculo de un español literario en visible transformación. Se ablandan, se ensanchan y remoldean los usos consagrados. Ese sentir como inestables las fronteras del idioma - y el obrar en consecuencia-irritará a quien suponga que el español ha nacido con la Academia (y suponga además que la Academia nada ha tenido que ver con Francia), pero se ajusta muy bien a una visión amplia del pasado y a la convicción de que el presente es, para esta lengua de veinte países, una nueva época de libertad y apertura, de fecundos conflictos y vacilaciones entre formas concurrentes, de margen holgadísimo para la iniciativa de cada escritor. Tientan los desafíos al diccionario y a la gramática, a sus reglas demasiado seguras y de una pieza: que tal o. cual palabra se escribe con o $\sin b$; que hay que decir desquite y no revancba, trivial y no banal. El escritor moderno escogerá a su gusto entre desquite y revancha, entre trivial y banal, entre armonia y barmonia, entre Elena y Helena, entre pentélico y pentbélico, sin sujetarse a purismos, y atendiendo a motivos complejos y personales.

A Rubén nunca parece abandonarle esta conciencia de movilidad verbal, $y$ vemos a menudo oscilar su ahincado "filologismo" entre la curiosidad etimológica más acabadamente poetizada y los meros retruécanos y chistes - graves chistes, a veces. En carta a Julio Piquet, setiembre de I9I4, habla con dolor de la guerra europea y de sus pro. yectos de campaña pacifista en América, que ha de empezar "por los Estados Unidos y el México devastado por fraternales rencores”. 5 „Fraternales! Unos meses antes, en carta al mismo Piquet, se había quejado de sus propias dolencias físicas: "A mí se me han declarado ya francamente Panchos Villas intestinos y riñones".6 Por otro lado, un par de cuidadosas páginas suyas comienzan así:

Señora: la miel de esa luna la elaboran las abejas del jardín azul, que liban entre los pétalos luminosos de las estrellas. Ellas van, en enjambres irisades, de los florecimientos de Aldebarán a las margaritas de la Osa, al clavel trémulo y cambiante de Sirio. ¡Pero las más ligeras, las más amables,

5 Epistolario, ed. A. Ghiraldo, Madrid, 1926, p. 85.

6 Barcelona, 22 de mayo de 1914, en Epistolario, p. 84. 
las más bellas y paradisíacas van a posarse en el cáliz atrayente, sagrado y misterioso de la rosa de oro de Venus!

Señora: el pintor Spiridón ha pintado el venturoso país de la felicidad: un lago manso, una barca, ella, él y el amor como remero. ¡Buena brisa, buen tiempo, señora!?

$Y$ a lo largo de un entrelazamiento de astros, flores y aves-Aldebiarán, la Osa, Sirio, Venus; rosa, lirio; paloma, ruiseñor- la "Canción" entera se nos aparecerá construida sobre un gran juego lírico de palabras: la miel de esa luna, la luna de miel.

Podemos conjeturar que, si un escritor inclinado a sutilezas de esa índole dice - como suele - "el Cristo",, no será por irreflexivo calco del francés. Ante la forma francesa, el escritor ha empezado sin duda por explorarla etimológicamente (el Cristo: el Mesías: el Ungido) y la ha transportado luego, tal cual, a su propia lengua. Otras veces, Rubén considera necesario preparar mejor a sus lectores, y lo hace con graciosa pedagogía. Si empieza por contarnos que en cierto barrio de París en que él ha vivido "está el cerebro, está la cabeza", aclara a continuación: "Por algo, en el argot parisiense, sorbonne quiere decir cabeza".9" Pensando en un público alerta, familiarizado con distintas lenguas, no hay para qué explicar palabras como grisetalo o plafón, ,1 $^{10}$ y puede Dario atreverse a plurales como "strausses locos"12 y a femeninos como reporteresa ${ }^{13}$ o hasta principesal4 y a otros derivados como maelstrómicalis y sbylockismo. ${ }^{16}$ Puede, por último, confiado en un tipo de lector para quien son habituales estos contactos interlingüísticos - los colegas porteños, digamos, de La Nación-, entretenerse dejando el término extranjero a medio cocer, y hablar, no de la calamidad hispana de la holgazanería,

7 "La canción de la luna de miel", en Poemas en prosa, ed. A. Ghiraldo y A. González-Blanco, Madrid, s. a., p. 29.

'B Así en "El árbol del rey David", Cuentos completos de Rubén Dario, ed. E. Mejía Sánchez, México-Buenos Aires, 1950, p. 156; "Un sermón", Cuentos, p. 178 (comp. p. 179: "Vicario de Cristo"); "En la batalla de las flores", Cuentos, p. 208; "La leyenda de San Martín, patroro de Buenos Aires", Cuentos, pp. 264 y 267 (comp., en la misma p. 267, "hijo de Cristo").

9 "Hombres y pájaros", en Cuentos y crónicas, Madrid, 1918, p. 96.

10 "Noches del Victoria", en Prosa dispersa, Madrid, 1919, p. 62, donde Rubén ni siquiera la subraya ni la entrecomilla.

11 "En Chile. Un retrato de Watteau", Cuentos, p. 47, y "El velo de la reina Mab", Cuentos', p. 52. En cambio, "el plafondo de zafir". ("el cielo') en "Hay un instante..." de Guillermo Valencia (Obras poéticas completas, pról. de B. Sanín Cano, Madrid, 1948, p. 632).

12 "El humo de la pipa", en Cuentos, p. 117.

13 " "Charles A. Dana", en Prosa dispersa, p. 83.

14 "Libros nuevos", en Prosa dispersa, p. 94.

15 La caravana pesa, Madrid, 1917, p. 33.

16 "La joven literatura", en España contemporánea, p. 83. 
sino de la del faineantismo;"17 no de los espectadores atónitos, sino "abasurdidos, como diría Roberto Payró" ante algún improvisado baile, ${ }^{18} \mathrm{y}$ no de unos rostros ingleses y norteamericanos, sino de "congestionados johmbulles y atroces tiosamueles" 19 Un paso adelante en ieste camino de la semiadaptación ingeniosa, y flatitud viene a refundir flat y platitude, 20 mientras que los je-m'enfichistes se transforman sin más en nadameimportistas.21 De I904 data La lucha por la vida, la trilogía de Baroja, pero desde mucho antes la frase darwiniana, en traducciones, glosas, parodias, ha estado circulando por todas partes en contextos conversacionales y epigramáticos. Ese es justamente el tono en que un personaje de $A$ la recberche du temps perdu, Brichot, llama al cardenal de Retz "ce strugle [sic] for lifer de Gondi".22 Pues bien: ya en I894, y con intervalo de pocos meses, Rubén Datio y José Asunción Silva coincidían en un pintoresco ensayo de hispanización del giro inglés. Darío comenta, el 20 de febrero, un telato argentino y, aplaudiendo la conducta de su protagonista, se refiere a él como "ese struglforlifero [sic], ese selfmade mant".23 $\mathrm{El} 7$ de octubre, Silva, joven secretario de la legación de Colombia en Caracas, describe a Baldomero Sanín Cano la prosperidad de Venezuela: "Usted, que... no es ambicioso, no sabe cómo es la fiebrecita de ganar dinero que le entra a un struggle forlifero cuando le pasan por las manos onzas peluconas y luises nuevos y se acuerda de que lo que corre en su tierra son los papelitos grasientos y el níquel de a medio". ${ }^{24}$

Al ansioso de modernidad, todo le sirve para salir de aventura más allá de las murallas académicas. Para Darío, todo ayuda a conquistar

17 "La joven aristocracia", en España contemporánea, p. 306. La omisión del acento, probablemente deliberada, contribuye a subrayar la hispanización del término.

18 "Ia fiesta de Velázquez", en España contemporánea, p. 146. Así se refiete en "Madrid" (España cantemporánea, p. 26) a los "ministros que taquinan la musa" (cursivas de Darío).

19 "La pesadilla de Honorio", en Cuentos, p. 233.

120 "La crítica", en España contemporánea, p. 300 . No parece que sea errata por platitud, ni que, por otro lado, quiera tampoco sugerir flatus ni flato. El contexto lo centra todo en la idea de "la más completa chatura".

21 "El modernismo", en España contemporánea, p. 273.

222 Marcel Proust, Sodome et Gomorrbe, t. 2, 88a. ed., Paris, 1935, p. 118.

23 "El Provincianito", La Tribuna, de Buenos Aires, en Escritos inéditos de Rubén Darío, ed. E. K. Mapes, New York, 1938, p. 39. Con más timidez, Rubén da original (struggleforlifers) y traducción en "Jacinto Octavio Picón", Cabezas, Madrid, s. a., p. 96. Utiliza además, por separado, la forma inglesa básica: "en una triste struggle-for-life ("Impresiones de Salón", en Parisiana, Madrid, 1917, p. 194), y desde luego la española, "la lucha por la vida" ("La joven literatura", artículo fechado el 3 de marzo de 1899, en España contemporáned, p. 78).

124 José Asunción Silva, Poesias completas y sus mejores páginas en prosa, pról. de A. Capdevila, Buenos Aires, 1944, p. 222. 
palmo a palmo la vaga tierra de nadie. Es como si el idioma hubiese recobrado la feliz inestabilidad de quién sabe qué tiempos antiguos en que fuera lícito escoger libremente entre amáts y amás, entre amaros y amarvos, entre dulzura, dulzor y dulcedumbre. Tan aficionado a viejos autores españoles como a modernas "incursiones poliglóticas y cosmopolitas", 25 Rubén se mueve gozoso, y con aplomo singular, en un laberinto de posibilidades. Es el suyo un casticismo raigal, seguro de sí, pronto a incorporarse riquezas variadísimas, guiado por una prodigiosa capacidad de absorción y re-creación y por un no menos prodigioso sentido del matiz oportuno. "Eres un profesor de Energía..."26. Rubén no se contentará con traducir, para aplicarlo a Theodore Roosevelt, el stendhaliano "protesseur d'énergie".27 Llegado el momento —el de "La Cartuja"-, vuelve, sí, sobre su imagen de la oda a Roosevelt, sólo que para transfiguratla decisivamente:

la soledad que amaba Jeremías, el misterio profesor de llanto.28

¿No es éste, en Rubén, un aspecto más de la continua movilidad de su estilo, tan abundante en auto-imitaciones y auto-caricaturas? Dentro

25 El viaje a Nicaragua e Historia de mis libros, Madrid, 1919, p. 204.

26 "A Roosevelt", Cantos de vida y esperanza, en Poesias, p. 640.

27 Menéndez y Pelayo lo atribuía vagamente al propio Stendhal; véase Arturo Marasso, Rubén Dario y su creación poética, Buenos Aires, 1954, p. 412. Marasso señala ahí un muy anterior "catedrático de valentía": Ruy Díaz de Vivar, visto por Juan Rufo. ¿No es curioso que "Almatuerte", el hosco y ascético Pedro Palacios, viera a su vez en la mujer una "catedtática de besos" ("En el abismo", estr. 23, en Obras completas. Poesías, I, ed. A. J. Torcelli, Buenos Aires, 1928 , p. 98)? Marasso, en fin, cita al Maurice Barrès de Les déracinés (para quien ese profesor de energía sigue siendo Napoleón), a Péladan (Leonardo da Vinci, "incomparable profesor de energía"), - a Maurras (variante: "profesor de serenidad"). No parece que Darío piense aquí en Stendhal. Si no a Barrès, quizá al barresismo apunta con su plural "los locos de hoy". "Catedrático de gozo dionisíaco", llama Rubén a Nietzsche ("Miss Isadora Duncan", en Opiniones, Madrid, 1918 , p. 161).

28 "La Cattuja", Canto a la Argentina y Otros poemas, en Poesias, p. 825. El juego sobre "profesor de..." reaparece en Ortega, que llamará "profesores de melancolia" a los judíos ("Shylock", julio de 1910, incluido luego en Persondas, obras, cosas, 1916, y en Obras completas, t. 1, 6a. ed., Madrid, 1963, p. 525) y en Antonio Machado, que cantará a un sabio mexicano:

\footnotetext{
No es profesor de energía

Francisco de Icaza,

sino de melancolia
}

en sus "Soledades a un maestro" (Nuevas canciones, en Obras, México, 1940, p. 339). Antonio Díaz-Cañabate, Historia de una tertulia, Valencia, 1952, p. 14, cita cierta dedicatoria de Gerardo Diego "A José María de Cossío, profesor de entusiasmo". 
de su vasta obra, personajes como el bíblico Nemrod, cazador ante el Altísimo, se trasladan de un contexto a otro en incesante metaformosis. Hablando a Roosevelt, y con reiterada alusión a sus hazañas cinegéticas, amonesta el poeta al atrevido riflero contra la ilusión de ser el Riflero invencible, ${ }^{29}$ pero ya en 1895 , enumerando las recientes candidaturas a "inmortal" de la Academia Francesa, recordaba a sus lectores la del vencedor, Houssaye, y junto a ella, por encima de ella, la de Verlaine, que estaba "cerca de la muerte y de la inmortalidad" (el Pauvre Lélian murió en r 896) y la de Zola, "el fuerte cazador" que no lograba pasar de "candidato perpetuo". ${ }^{30}$ No es eso todo, aun omitiendo otros "fuertes cazadores" de Rubén. El mismo Theodore Roosevelt se nos presenta, observado con ojos franco-hispanoamericanos, en una de las crónicas de Todo al vuelo. ${ }^{31}$ Roosevelt es aquí muchas cosas $\mathrm{y}$, resumiéndolas, es "polifacial y multiactivo" (p. I54). Pero una vez que la pluma de Darío se ha cebado en este modo de derivaciones y composiciones, seguirá cargando las tintas, y el "jovial Nemrod" (I55) pasa a ser finalmente "hipopotamicida y rinoceroctono" (I57). ¿No aparece y reaparece así Victor Hugo, con inesperada varieded de humor, rigiendo vastos imperios de poesía como un Carlomagno moderno? El comentario de Rubén sobre "el divorcio de Jeannette" - la nieta de Hugo, la inmortalizada por L'art d'être grand-père-32 pinta retrospectivamente al poeta francés jugando con la niña y sirviéndole de cabalgadura ("Résigné, comme on dit que le fut Henri Quatre, / Papapa sous le joug se courba doucement"), y en estas ligeras páginas el abuelo, el Papapa, es "emperador de la barba florida", como lo había sido años antes -ipero con qué suntuosidad! - en el "Pórtico" a Salvador Rueda.33

Modernidad: dinamismo, integración. Toda la geografía, y en ella Francia como el país que mejor realiza y difunde entonces ese anhelo de

29 "A Roosevelt", p. 641. En "Manuel Ugarte" (Cabezas, p. 74), como quitando importancia a su propio poema en comparación con las "cosas bellas y proféticas" de Martí "sobre el acecho de los hombres del norte", con los gritos terribles de Vargas Vila y con los análisis de Ugarte, escribe Rubén: "Yo mismo, hace ya bastante tiempo, lancé a Mr. Roosevelt, el fuerte cazador, un trompetazo, por otra parte inofensivo".

30 "El sillón de Leconte de Lisle", en Prosa dispersa, p. 14.

31 Madrid, s. a., pp. 153-161: "Roosevelt en París".

32 Prosa dispersa, p. 99.

33 Prosas profanas, en Poesias, p. 585. 
totalidad; lo francés entra hasta en la hispanofilia de Rubén. ${ }^{34}$ Toda la lengua española, movediza y en crecimiento, y observada por el poeta con vivo interés en su desarrollo a través del tiempo y del espacio. En España, no sólo el español de Madrid. Darío lee con atención los poetas de Asturias, y siente como propia y alaba como ejemplar la estudiosa curiosidad regionalista de un Jovellanos, el de la "notable instrucción para la formación de un Diccionario bable".35 Y en América, lengua y cultura se le aparecen unidas, como precioso legado común de todas las Españas. Darío se complace en mostrar - pero evitando abusos de hispanomanía simplificadora-cómo las viejas tradiciones locales enlazan a Nicaragua con la historia de la Península. Una de esas tradiciones afirma que en Nicaragua "estuvo un hermano de Santa Teresa de Jesús, y que él fue quien llevó la imagen que aún hoy se venera en el santuario de Nuestra Señora de la Concepción de El Viejo. Pudiera suceder, y quizá de él desciendan algunos de los Cepedas del país".36 Y enseguida agrega que también anduvo por allá un Loyola, aunque Rubén no cree que fuera pariente de San Ignacio. Pero, tras estas sinuosas afirmaciones, quien sí despierta el entusiasmo de Darío es alguien que "en realidad estuvo allá, e hizo perdurable obra de bien, pues si no era un santo era un héroe: Fray Bartolomé de las Casas". A Rubén le es particularmente grato ver consagrada por la historia la grandeza del dominico "que en el Capitolio de Washington tiene estatua, y cuyo nombre brilla con singular luz entre los de los bienhechores de la Humanidad".37 Brillo singular: los religiosos venidos de España en los dos primetos siglos le merecen a Rubén, en general, tan pobre opinión como la codicia y crueldad de capitanes, encomenderos y gobernadores. "...Por todas partes está el dominio de las armas y la cogulla. "El fanatismo imperaba". 38 "El período colonial es sombrio para la vida intelectual" 39 "La historia parece, en

34. Comp. Enrique Anderson Imbert, Estudios sobre escritores de América, Buenos Aires, 1954, p. 186.

35 Todo al vuelo, Madrid, sa., p. 91 y sigs.

36 El viaje... e. Historia..., p. 50.

37 El viaje...., pp. 50-51. En éste y otros pasajes, Dario sigue de cerca, y cita ocasionalmente, la Historia de Nicaragua de José D. Gámez. Tengo a la vista la edición de Managua, 1889, con sus acusaciones a la crueldad de los conquistadores (pp. 128 y 132-133), a la poco evangélica acción del clero español en Nicaragua (pp. 134 v 147 sigs.), a Las Casas como gloriosa excepción (pp. 131 y 148). Compárense las palabras de Rubén con estas de Gámez: "En el Capitolio de Washington... ha sido colocada, por disposición del gran pueblo americano, la estatua de Fray Bartolomé de Las Casas, pensándose, con justicia, que la radiante figura del piadoso obispo..." (p. 148).

38 Comp. Gámez, pp. 288-290.

39 Comp. Gámez, a propósito del reinado de Carlos III: "El desarrollo de las luces fue muy rápido.. La Inquisición se escondía ya del pueblo y huía de 
cambio, iluminársele a Rubén a partir de Carlos III, incluso lo tocante al papel de la Iglesia: "fueron también clérigos los que, como antaño la sombra, hacían ahora la luz" ${ }^{4}$ Rubén fija la mirada en esa luz cuando sentencia en I899: "El siglo XvIr fue más culto que este fin de siglo. . ."41

El español de todas las épocas ofrece al poeta moderno mil incitaciones. "Gústame de emplear en lo inventado / el sutil arcaísmo. . "42 La declaración de Darío es exacta y, en lo mejor de su obra, suele ser asombrosa la sutileza de sus arcaísmos. Pero aquí y allí asoman ingenuos arrastres de lecturas españolas, o españolizantes: casticismos forzados, casticismos de puristas.", Hasta en medio de la lírica prosa de su "Edgar Allan

la luz, como avergonzada y arrepentida de sus propios errores..." (p. 285); "En los primeros años que siguieron al descubrimiento de Nicaragua, la población se hallaba, en cuanto a letras, en completas tinieblas... La instrucción clerical sólo se limitaba a las castas privilegiadas" (p. 288); "La sabiduría y la ciencia no pasaban nunca más allá de los dinteles de la sacristía... Así se explica que explotara la credulidad pública con tanto aplomo..." (p. 289).

40 El viaje..., p. 52. Comp. Gámez, p. 285: "Un fraile [Torquemada] había sumergido a España en las tinieblas de la ignorancia, y fue otro fraile [Feijoo] quien alejó las tinieblas y derramó sobre ella la luz de la moderna civilización". 41 España contemporánea, p. 246 . El ángulo de observación es aquí distinto. El crítico denuncia la "preponderancia clerical" como rémora de la Ilustración dieciochesca y como amenaza que se ha agravada en los tiempos modernos: "Hay multitud de colegios regenteados por Ordenes religiosas... La experiencia ha demostrado aqui y en otras muchas partes que los internados son funestísimos" (p. 245). Una descripción de los festejos de Semana Santa (pp. 94-102) da pie a Darío para discurrir en zigzagueantes páginas sobre la religiosidad y la irreligiosidad hispánicas: "País de Carlos V, de Felipe II, de Carlos II el Hechizado; país de la expulsión de los judíos y de los moros: su fe no llega muy a lo profundo" (p. 102). Bajo el catolicismo español subsiste lo pagano, lo romano e inquisitorial, la "koránica" asociación de la cruz y la espada: lo musulmán por 'fuera y por dentro. "En ciertos templos andaluces el catolicismo deja ver a través - de sus adornos y símbolos las líneas y arabescos moriscos: en las almas pasa algo semejante" (p. 102). Pero ni toda su crítica de España quiere ser tan honda y grave, ni la América hispana se le aparece siempre como pueblo que "vive de luz, de fuego, de perfume, de amor" ("A Roosevelt", p. 640). Darío se entretiene en mostrar unidas, por su raíz, la pompa y solemnidad española y la hispanoamericana. Comentando a don Marcelino y su estudio de la "primitiva literatura de Chile", icon qué gusto cita Rubén, no simplemente el Compendio bistorial de Jufré del Águila, sino el Compendio bistorial del descubrimiento, conquista y guerrd del Reyno de Chile, con otros dos discursos. Uno de avisos prudenciales en las materias de gobierno y guerra. $Y$ otro do lo que católicamente se debe - Sentir de la astrología judiciaria. Dirigido al Excmo. señor conde de Chinchón, virrey destos reinos del Perhí, Tierra Firme y Cbile, del capitán Melchor Xufré del Äguila!

4: "A Ricardo Contreras", Epistola y poemas (Primeras notas), en Poesias. p. 337. Merecerían estudiarse las variadísimas prolongaciones de ese gusto juvenil hacia su obra ulterior, como ha hecho Mejía Sánchez con las que arrancan de los tres primeros cuentos de Darío. Véase. la nota que sigue.

43 Para la prosa narrativa de Rubén, of. Letras bispánicas, México-Buenos Aires, 1958 , p. 242, y en especial Ernesto Mejía Sánchez, Los primeros cuentos de Rubén Dario, México, 1961, pp. 39, 60-62, 76, 107-108, 122 y 151. 
Poe", 44 un arranque particularmente conmovido asocia el recuerdo de su "Stella" (Rafaelita Contreras) con las "liliales vírgenes" cantadas por el "príncipe de los poetas malditos": "¿Por qué vino ta imagen a mi memoria, Stella, Alma, dulce reina mía, tan presto ida para siempre. . . " Presto, adverbio, pudo acaso parecerle a Darío más solemne que pronto. Es la misma palabra que, también como adverbio, habia utilizado Rubén en un cuento de I888, "El humo de la pipa": "con el ardor de las caricias las flores se marchitaban presto". $45 \mathrm{Y}$ es el mismo presto que aparece ya en "La entrada de Jerusalén", unas páginas de La fin de Satan libremente traducidas por Darío en verso y publicadas en I886: " $¡$ Presto voy a la muerte caminando!.. ${ }^{46}$ Para el lector que no tenga a la vista el original francés, este presío encierra-justamente porque no se traza límite claro cntre adjetivo y adverbio, entre 'preparado, dispuesto, listo' y 'sin tardanza, pronto'- una dualidad semántica que no hallábamos en el presto de "Poe" ni en el de "El humo". Pero ésta no parece haber sido la interición de Rubén; las palabras que Victor Hugo pone ahí en boca de Jesús son muy simples e inequívocas: "Je vais bientôt mourit". 47

Con los clásicos y medievales, la Biblia española y sus sorpresas de léxico. No sólo términos como el gazofilacio del Evangelio ('tesoro del templo', en Matcos, XII, 4I, y Lucas, XXI, I), que con tan oratorio esplendor resuena en el Canto a la Argentina, 48 sino como esa extraña varona ('mujer') a que el traductor ha acudido para conservar el juego morfológico y etimológico entre las dos palabras hebreas is $b^{49} \mathrm{e}$ ishá ('hombre' y 'mujer'). Adán, ante el cual ha desfilado la inmensa compañía de todos los animales del campo y el cielo, y que a todos ha puesto nombre, cae en divino letargo $y$, tras una operación quirúrgica no menos divina, recibe el regalo asombroso: Eva. Esa sí es compañía verdadera, proclama el primer hombre. En la versión de Bover y Cantera: "Esta vez sí que es hueso de mis huesos y carne de mi carne!/A ésta se la llamará varona, porque de varón ha sido tomada". 50 No está mal que el lector moderno asocie esta palabra con la prosa de Unamuno y Borges; lo malo sería olvidar la de Rubén. Pues los tres poetas son tres grandes frecuentadores

44 En Los Raros, p. 20.

45 Cuentos completos, p. 118.

46 Poesias, p. 319.

47 La fin de Satan. Dieu (Oeuvres complètes de Victor Hugo, Poésie, XI), Paris, 1911, p. 113.

48 Poesias, p. 799.

49 Comp. la primera sílaba de Is-cariote. Judas es "el hombre de Keriot". En "San Antonio y el Centauro", de Guillermo Valencia (Ritos, en Obras poéticas completas), p. 107, "el de Kerioth".

50 Génesis, II, 23 (Sagrada Biblia, Madrid, Biblioteca de Autores Cristianos, 3a. ed., 1953). 
de la Biblia. Claro que, limitándonos ahora al Varona de Rubén Darío, hace falta mirar más de cerca la palabra y su contexto. Ante todo, la mayúscula: Varona. En ese raro arcaísmo quiere concentrar el joven poeta la soberana obsesión: "Varona inmortal, flor de mi costilla".51 Pero Rubén no se queda ahí, y a su nuevo mito, vistoso y personalista ( $m i$ costilla!), sigue con elegante y galante concisión una parodia del "Homo sum..." de Terencio. Sólo estas dos palabras, "Hombre soy", en que la primera, gracias al contexto, deja de significar 'ser humano' y cobra el preciso e intencionado sentido de 'varón'.

Es natural que, evocando Darío la figura de Valle-Inclán, la palabra arcaica venga a redondear su frase. Aun en tiempos adversos - nos asegura Rubén- este gran don Ramón ha sido, no sólo el cabal escritor, sino "el caballero, el fidalgo".52 Para precisar, exaltándola, la idea de caballero, hubiera bastado bidalgo; con fidalgo se refuerzan sus estéticas resonancias. Quizá la rima haya sugerido alguna vez el utilizar conceto en lugat de concepto, como en los versos de Rubén a "Vargas Vila en su librería"; 53 sólo que en la estrofa inmediata aparece también un se apropincuch gratuito, totalmente ajeno a las invitaciones del consonante. Juntos estos dos rasgos ( $\mathrm{y}$ otros que nada tienen que ver con el arcaísmo léxico ni con las sugerencias de la rima), insinúan no sé qué vaga sonrisa y reticencia en el elogio de Rubén al escritor colombiano.

Por lo demás, a lo largo de la obra toda de Darío, la imitación profunda, y aun la más expresa y deportiva, de los viejos autores españoles admite toda suerte de libertades. ${ }^{54}$ Desde su adolescencia, el escritor se asimila las maneras de antaño y procura continuarlas creadora y renovadamente. $\mathrm{Y}$ el poeta seguro de sí, respetuoso y amante de los clásicos, y deseoso a su vez de ejercitar la mano en la imitación, se divierte fraguando cómicos pastícbes. Ahí tenemos sus versos juveniles de "La poesía castellana" y "En la última página de El romancero del Cid"; 55 ahí su "Erasmo a Publio", en que Rubén puede todavía decir "el placer finido" 56 y construir:

Bajó Nabuco, emperador soberbio...

cayendo de su trono. Esto vio el pueblo

\footnotetext{
51 "Palabras liminares" de Prosas profanas, en Poesias, p. 546.

52 "Algunas notas sobre Valle Inclán", en Todo al vuelo, p. 58.

53 Poesías, p. $1,037$.

54 Y lo característico de Rubén no setá tanto la desaparición gradual de sus arcaísmos como la conciencia, a menudo itónica, con que entren luego en sus escritos: su creciente dominio y, por tanto, la pluralidad de intenciones con que el poeta los emplee.

55 Poesias, pp. 258-267 y 168.

56 Epistolas y poemas, en Poesias, p. 363.
} 
de la muelle y, maldita del Dios justo, transformada en rüinas, Babilonia ...;57

ahí su epístola a Jaimes Freyre,58 de 1895 , fruto tardío de la misma rama. Ligeros arcaísmos de sintaxis entran con frecuencia en la prosa y el verso humorísticos de Rubén (y no me refiero sólo al do los comienzos), pero entran además, esporádicamente, en pasajes de muy otra tesitura. Al empezar su "Cuento de Pascuas", el narrador nos dice que su personaje, el alemán Wolfhart, había tratado en Buenos Aires "a un gran poeta y a un mi antiguo compañero"s9 $\mathrm{y}$, pocas páginas después, que había logrado fabricar cierto misterioso elixir "con ayuda de un su amigo alquimista".60 En la conjugación verbal, las intercalaciones entre el auxiliar baber y el participio pasado se prestan a experimentos más flexibles $y$ originales -a veces, calculado desafío a los hábitos del español moderno-: "He, sí, cantado aires antiguos" y "he, cada día, afianzado más mi seguridad de Dios"; 61 "Su libro me ha, sencillamente, encantado" y "El ministro de Guatemala, D. Fernando Cruz, ha, en sus tiempos floridos, pulsado la lira".62 "Washington Irving os habrá, de seguro, conducido por estas encantadoras regiones". ${ }^{63}$

57 En Poesias, p. 364. Pero ya el muchacho que escribe el "Moderno idilio. Francisco y Elisa" (Poesías, p. 210) puede bromear con la propia sintaxis seudogongotina invocando la "autoridad" de La gatomaquia:

y ni llora siquiera

mi templada de dulces cuerdas lira.

58 Poesias, pp. 967-970.

(En una de fregar cayó caldera.)

59 Cuentos completos, p. 301.

60 Cuentos completos, p. 305. En "La novela de uno de tantos", Cuentos completos, p. 148: "un mi compañero de colegio"; en Autobiografía, Madrid, 1920, p. 2: "un mi tatarabuelo". Frecuentes las intercalaciones entre artículo y sustantivo: "el, más que purgatorio, infierno del alcohol" ("Lal hija [sic, por "La vida"] de Verlaine", en Todo al vuelo, p. 200), "el todavía oculto, pero admirable poeta, Ricardo Jaimes" ("Bajo relieves, de Leopoldo Diaz", en Escritos inéditos, p. 81). Un "desde hace tanto tiempo anunciada e iriacabada tragedia" ("Algunas notas sobre Jean Moréas", en Opiniones, p. 76). Habla Rubén de México, y recuerda que allá "manda el legendario y justamente alabado por Tolstoi, general don Porfirio Díaz" ("Algunas notas sobre Valle Inclán", en Todo al vuelo, p. 56). Es muy probable, aunque la puntuación no resulte del todo clara, que a igual molde sintáctico responda esta frase de su alegato contra el índice expurgatorio de Nordau: "El admirado universalmente por su alta crítica artistica, Ruskin, queda condenado" ("Max Nordau", en Los Raros, p. 192). Un refinamiento más le hace acaso combinar ese orden de palabras con cierta leve sugerencia de "creatura bella bianco vestita". Sarah Bernhardt - explica Rubén - ha sabido transfigurarse genialmente en los más variados personajes masculinos: en Lorenzaccio, en el Aiglon, en "el de negro vestido príncipe de Dinamarca" ("Sarah-Nerón", en Todo al ruelo, p. 22).

61 "Dilucidaciones", en Poesías, pp. 697 y 698.

62 Carta a Alberto Insúa, 20 de agosto de 1907, en Epistolario, p. 117, y La caravana pasa, p. 169.

63 "Granada", Tierras solares, en Obras completas, t. 3: Viajes y crónicas, ed. M. Sanmiguel Raimúndez, Madrid, 1950, p. 904. 
Hallamos así, en su prosa y su verso, una escala amplísima de trasposiciones, entre las paródicas y las originales, entre las casi imperceptibles y las más detonantes y cómicas. $Y$ su arte insuperable de los contrastes, sorpresas y choques sintácticos se funde delicadamente con muchos otros rasgos. En una misma estrofa de "Eros", en el "Tríptico" de sonetos con que Darío celebra en I9I2 su tierra natal, 64 las figuras femeninas evocadas, y hasta el nombre del puerto nicatagitense de Corinto, preparan el ánimo a la deliciosa tensión del último verso, con su sintaxis ultraclasicista - ja qué distancia de la de "Erasmo a Publio"!- y su sabroso topónimo indio al final:

En cada mujer miro como una ninfa griega;

en poemas sonoros sus frescas gracias pinto;

y esto pasa al amor del puerto de Corinto,

$o$ en la rica en naranjas de almíbar, Chinandega.

Darío es maestro en la intercalación ambigua y leve, en la que resulta difícil decidir si entra o no cierto dejo humorístico. Es el contexto lo que nos hace sonreír ante frases como "la mal aconsejadora melancolía"; 65 estas palabras suenan en medio de un "Elogio de los gordos", bienaventurados porque no dan entrada en su pecho a la mala consejera. Maestro en el golpe inesperado de sintaxis arcaizante en el momento más dramático de un poema (acompañado del golpe de versificación, el brusco paso de la rima grave a la aguda); es el terrible lobo quien cuenta su historia al dulce Francisco de Asís denunciando, como culpables de su renovada, implacable ferocidad, a los hombres con quienes procuró convivir:

$Y$ recomencé a luchar aquí, a me defender y a me alimentar...66

(comp. análogo toque extraño y primitivo en las Voces de gesia de ValleInclán: "No se hiló la lana sin la cardar,/Ni se cogía trigo sin lo sembrar"). ${ }^{67}$ Maestro en el salto atrás, en el salto histórico al corazón -al lejano núcleo etimológico - de una palabra tan "opaca" para el hablante de hoy como cínico. Cuando Rubén, comentando la regalada vida de los perros de lujo en París, utilice el término en un giro como "cementerio cínico", to lo que burlescamente querrá decir es 'cementerio de perros'.

\footnotetext{
64 "Tríptico nicaragüense", en Poesías, p. 1,061.

65 Poemas en prosa, p. 126.

66 "Los motivos del lobo", en Poesías, p. 837.

67 Madrid, 1911, p. 19.

68. La caravana pasa, p. 14.
} 
Para poner en cómica vibración el contacto entre lo actual y lo remoto, sea en versos como los de "La poesía castellana", sea en los dirigidos a Jaimes Freyre, no basta remedar vagamente el vocabulario y sintaxis de la fabla antigua. Importa que las rarezas de pronunciación y escritura completen el juego, en que suele además incluirse el de la alusión a circunstancias muy locales y modernas:

Señor Ntro. Xaimes Freyre...

Vos manda decir Rubene

Que el justillo de contraye

Vos lo mandará muy pronto

Pues en esos malos ayres

Teme vos fieran los yelos

Con pícara enfermedade...

Hoy, a dos días de Mayo

(Después del día sociale)...69

Pero, bromas aparte, la lectura de los clásicos ha dejado también en los versos de Dario huellas gráficas que en él se asocian con su viva experiencia de la lengua oral (no' sólo académica) y con el intento, compartido por otros poetas de su época y la inmediata anterior, de agilizar los metros españoles adaptando a ellos peculiaridades del francés, y quizá también del italiano. Cuando leemos en Darío un endecasílabo como "que pone el sol en l'alma del panida", un' eneasílabo como "Ten l'alma lista a lo improviso", un hemistiquio heptasilábico como "l'agua de una cisterna", ${ }^{70}$ este uso de la elisión y el apóstrofo parece rozar el del italiano o el francés; pero, sin salirse Darío de sus clásicos españoles, bien a su alcance estaban las variadas iniciativas de este género en lo tocante a prosodia y tipografía poética. En la primera égloga de Garcilaso: "y tú, rústica diosa, ¿dónde 'stavas?", y en la segunda: "... se levantan/del gran sueño y s'espantan, alegrando/el ánimo...";71 en Jiménez Ayllón: "A los de l'alta casa de Toledo" y "iEn Frisa siend'os Marte muy propicio"; 72 en Herrera, que marca aquí con apóstrofo la sinalefa, pero sin omitir ninguna de las dos vocales: " $T$ Tal me tiene'el Amor preso y rendido!" o "Mira la'amarillez de mi semblante". ${ }^{73}$ Es gracioso que $E l$ Mon-

69 Poesias, pp. 967-970.

70 "Revelación" (El carto errante); "A mi joven amigo...", de 1908, y "Los olivos", de 1913, en Poesías, pp. 712, 1,036 y 1,073.

71 Garcilaso de la Vega, Obras completas, ed. E. L. Rivers, Columbus, Ohio, 1964 , pp. 80 y 130

72 Sonetos a illustres varones... por Diego Ximénez Ayllón..., Amberes, 1569, sin fol, ed. fotogr. de A. Pérez Gómez, Valencia, 1959.

73 Rimas inéditas, ed. J. M. Blecua, Madrid, 1948, pp. 135 y 196. 
serrate comentara tan extremado refinamiento erudito de su época - nos lo recuerda Oreste Macrí- refiriéndose el mismo Virués, en ese pasaje, a "los doctos y curiosos modernos que l'han inventado". ${ }^{74} \mathrm{Y}$ ! en años posteriores, Quevedo: "Y cuando l'ara en sangre humosa bañas" (soneto "Para comprar los hados..."), "adoro l'alma, admiro la belleza" (soneto "Puedo estar apartado..."), "suplir el sol, sostituir l'aurora" (soneto "Bien pueden alargar..."), 75 y Francisco de Rioja: "qu'el tierno pie ocupaba", "a l'alma más soberbia i más elada", "el mar con l'aura que Ocidente envía", "envidia de la llama y de l'Aurora".76

Antes y después de Rubén, otros hispanoamericanos han querido lanzarse muy a fondo por ese camino. En Páginas libres, de Manuel González Prada,77 leemos: "l'Alemania", "l'acción", "l'amargura", "la' renilla [¿errata por "l'arenilla"?] del mar",78 y también "un'antinomia" y "est'atmósfera";79 además: "d'empresas", "d'espaldas", "d'Herna$n i "$, "d'escribir", 80 y "s'enorgullece", "s'encuentran", "s'exhala", "s'evapora", "s'estiende", "s'eximen".81 Franz Tamayo, con unidad de criterio, utiliza en su "Dedicatoria":82 "l'alba espuma" (p. 248) y "l'áurea" (25I). Después de Darío abundan los intentos análogos, no pocas veces con exceso de sistema y con arbitrariedades y vacilaciones. Älvaro Armando Vasseur, traduciendo el "Coro" con que comienza el "Dialogo di Federico Ruysch e delle sue mummie", de Leopardi, parecería haberse propuesto, en el verso 9, mantener la elisión italiana ("l'arido spirto"): "L'árido espíritu, faltarle fuerzas siente", 83 sin ninguna visible ventaja

74 Cf. Oreste Macrí, Fernando de Herrera, trad. María Dolores Galvariato, Madrid, 1959, p. 346.

75 Obras completas, 1. Poesía original, ed. J. M. Blecua, Barcelona, 1963, pp. 62,524 y 514 .

76 Poesias, ed. C. A. de la Barrera, Madrid, 1867, pp. 246, 263, 200 y 241. Mucho queda por estudiar en lo que toca a la cronología de estos usos y a su relación con muy cambiantes concepciones de la lengua literaria. El texto de Fray Luis en el manuscrito de Jovellanos, que Macrí ha caracterizado como "classicheggiante-neoitalianista", presenta formas — "al'alma", "d'al", "estábat'ordenada", "que l'engendraste", "llegarl'al fin"- - que en conjunto concuerdan orgánicamente con grafías cultistas como "thesoro", "choro" (coro,) "Phelippe", "Scithia", "offenderme", "sancto", "fructo", empleadas en el mismo manuscrito (véase Oreste Macrí, Fray Luis de León: Poesie, Firenze, 1964, p. 289).

77 Ed. L. A. Sánchez, Lima, 1946.

78 Pp. 183, 242; los dos últimos ejemplos, en p. 291.

79 Pp. 215 y 69.

8:0 Pp. 87, 105, 176 y 207.

81 Los dos primeros ejemplos, en p. 203; los siguientes, pp. 204, 282, 290 y 291. 1966 .

82 En Porfirio Díaz Machicao, Prosa y verso de Bolivia, La Paz-Cochabamba,

83 "Diálogo de Federico Ruysch y de sus momias", en Gloria. Aventuras peregrinas. Madrid, 1919, p. 185. El texto italiano, en Prose di Giacomo Leopardi, 
métrica, porque, si en la traducción entran algunos versos de siete y once sílabas que recuerdan los de Leopardi, se introducen además muchos otros, irregulares, como el mismo verso citado. En la tipografía meticulosa de Guillermo Valencia: "Mas lo mejor del caso fue qu'en el rostro abierto..." 84 y, de parecida manera, "d'él", "d'ella", "d'ese", "d'entre", "d'embustes", "s'endurece", 85 frente a "l'aventura", "l'ambición", "l'atrabilis". 86 En Alfonsina Storni, dentro de un mismo endecasílabo se oponen "qu'eran" y "de esperanzas": "qu'eran a modo de esperanzas fieles". ${ }^{87}$ Claro que ningún mediano lector de versos necesita tan nimias indicaciones para leer correctamente "que eran", "la amargura" o "la ambición". En Rubén Darío resalta, por lo que atañe al uso de estas formas, su discreción y parquedad, y su contacto con la lengua hablada. El poeta no tiene por qué recurrir, en la escritura, a deste ni qu'este: confía en su lector. Pero en lugar de las formas trisilábicas "el alma", "el agua", Rubén sí pronuncia y escribe en verso alguna vez, como bisílabos, "l'alma", "l'agua". 88 Del mismo modo procede Gabriela Mistral cuando escribe "l'habla", "l'ansia". ${ }^{89}$ No se trata de una aparatosa subversión de la ortografía, sino de un mínimo retoque que apunta a consabidos idiomáticos bien firmes. Ambos poetas escogen, en esos casos, modos de pronunciación familiares a la lengua de América y España. "L'águila, siendo animal...", canta un popular octosílabo mexicano, y Martín Fierro se consuela a su vez cantando "como la ave solitaria" ("l'ave", en dos sílabas, naturalmente).

Cuando, al morir Dario, lo consagra Antonio Machado como "jardinero de Hesperia" y "ruiseñor de los mares", y asocia a su propio llanto los "corazones de todas las Españas", sigue fielmente el espíritu y aun la letra de Rubén. El argentino Sarmiento, contra las discordias que separaban a porteños y provincianos, decía ser porteño en las provincias y provinciano en Buenos Aires. Rubén, proclamando su fe en el renaci-

Milano, Sonzogno, 1874, pp. 109-113 (completo y corrijo la nota de Vasseur en p. 192).

84 Obras poéticas completas, p. 210.

85 Pp. 746 (y 832), 754, 830 (y 842), 786 y, para los dos últimos ejemplos, la misma p. 757.

86 Los tres casos en p. 754.

B7 Obra poética completa, Buenos Aires, 1961, p. 250.

88 Cf. nota 70.

89 Desolacion, New York, 1922, pp. 37 y 12. 
miento de una Hispania doble, o múltiple - -"en el propio solar y del otro lado del Océano, en el coro de naciones que hacen contrapeso en la. balanza sentimental a la fuerte y osada raza del norte"- -90 se afirma "español de América y americano de España". ${ }^{91} \mathrm{El}$ argentino y el nicaragüense viven sus paradójicas unidades duales, o múltiples; las realizan, en honda crítica y crisis. Rubén sabe, además, de su parentesco ideal con Sarmiento.

En plena época de raros y de Prosas profanas, es confortador espectáculo el de este Rubén Darío que, comentando elogiosamente a Menéndez y Pelayo en $L a$ Nación de Buenos Aires, rectifica sus datos, atempera tal o cual juicio sobradamente severo, aprovecha la coyuntura favorable para lamentar "el desconocimiento que de nuestro espíritu y vida hay en la Península" 92 y aun rompe lanzas, en réplica al maestro, por el español José Joaquín de Mora y, muy en particular, por Domingo Faustino Sarmiento, a quien vapuleaba Menéndez y Pelayo como al "principal representante de la demagogia literaria" en la polémica chileno-argentina de r842.93 Darío no escatima elogios a Sarmiento, a lo saludable de su acción, contra la esterilidad de un "bellismo llevado a sus mayores extremos". si Frente a los peligros de la academia y el purismo, Rubén exalta la posición activista y transformadora de Sarmiento, vitalmente engranada en lo actual y vuelta hacia el porvenir. "Escribir las ideas de Sarmiento en la lengua de don Andrés Bello: he ahí lo que había de buscar la nueva generación". 95 Pero lo mejor de Sarmiento ha triunfado, de todas maneras. $Y$ deben sentírsele agradecidos también aquellos que, aceptando su pensamiento renovador, están a la vez sanamente inquietos por el destino del castellano en América: "si existen quienes descuiden el cultivo de la lengua maternal, de nuestra hermosa lengua española, otros hay que se preocupan por ella deseando resucitar sus antiguos prestigios y aumentar razonablemente su fuerza y su gracia, en vocabulario, rítmica, plasticidad y matiz". ${ }^{96}$ Por último, si don Marcelino mira con cierto desdén la moderna literatura chilena y señala su uniforme prosaísmo, Rubén, impaciente, acumula retóricas interrogaciones ("¿Ha leído Menéndez y Pelayo.. ?", "¿Ha leído. .?", “Conoce. .?”) para denunciar lagunas de información aun en tan erudito maestro. Y la fe de Darío en

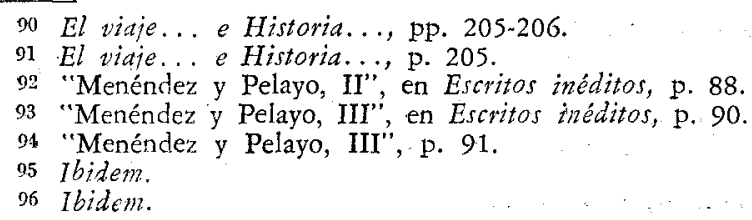


la promesa poética de Chile le hace terminar su artículo de La Nación con una irónica ocurrencia, retrospectivamente anti-bellista: "No todo es arideces y cosas prácticas en ese vigoroso Chile. Suele a veces cantar, al cläro de luna, sobre las balumbas positivistas, sobre los fárragos históticos, sobre las duras rocas del código, sobre la fría estatua calva del insigne Andrés Bello, un ruiseñor". 97

No hay por qué condenar los programas de independencia idiomática y cultural, si su meta es de ampliación y enriquecimiento, benéficos para el español de todas partes. El mismo Rubén no se propone otra cosa, en circunstancias distintas. Ni ha de pensarse que él rehuya lo que en la lengua literaria no sea una refinada "rítmica, plasticidad y matiz". Ahí tenemos, por lo pronto, giros tan expresivamente coloquiales como "esa perra suerte que nos perseguía" recordada por el hispánico narrador de "D. Q.", esto es, de la extraña y heroica historia de un don Quijote redivivo en la desastrosa guerra de Cuba.98 Ahí la prosa conversacional fuerte y simple con que comienzan "Las pérdidas de Juan Bueno":

.. Se llamaba así porque desde chico, cuando le pegaban un coscorrón por un lado, presentaba la cabeza por otro. Sus compañeros le despojaban de sus dulces y bizcochos, le dejaban casi en cueros, y cuando llegaba a la casa, sus padres, uno por aquí, otro por allá, a pellizco y mojicón, le ponían hecho un San Lázaro. Así fue creciendo hasta que llegó a ser todo un hombre. ¡Cuánto sufrió el pobrecito Juan! Le dieron las viruelas y no murió, pero quedó con la cara como si hubiesen picoteado en ella una docena de gallinas. Estuvo preso por culpa de otro Juan, que era un Juan Lanas. $Y$ todo lo sufría con paciencia, a punto de que todo el mundo, cuando decían: ;Allá va Juan Bueno!, soltaba la risa. Así las cosas, llegó un día en que se casó.99

97 "Menéndez †े Pelayo, III", p. 92. Casi lo mismo -quitada toda ironíaen "Un libro sobre Chile", Todo al vuelo, p. 241.

98 Frases, por lo demás, tan transparentes para el lector de España como para el de América. El cuento apareció, según me comunica Enrique Anderson Imbert, en el Almanaque de Peuser, de Buenos Aires. Lo publicó luego la revista española Don Quijote, año 8, no 8, del 24 de febrero de 1899. Ernesto Mejía Sánchez ha dado a conocer el texto reproducido por la revista argentina Fray Mocbo, Buenos Aires, 13 de eneto de 1920; puede verse en la Gaceta del Fondo de Cultura Económica, México, abril de 1966, pp. 8-9, precedido de una sustanciosa nota del mismo Mejía Sánchez.

99 Cuentos completos, p. 172. Cf. en esa misma página la nota de Mejía Sánchez, por la que sabemos que el cuento apareció en El Heraldo de Costa Rica el 13 de marzo de 1892. El tono en que narra Darío la historia de su Juan Bueno se acerca mucho al de "Juan Manso" - de intención y asunto análogos, aunque de diferente "teología" - con que Unamuno parece responderle un par de meses después. Unamuno publicó su cuento en El Nervión de Bilbao el 22 de mayo de 1892, según E. K. Paucker, en: Miguel de Unamuno, Cuentos, Madrid. 1961, Biblioteca Vasca. IX, t. 2, p. 212. "Juan Manso" lleva además este subtítulo, entre paréntesis: "Cuento de muertos". 
Ahí también, en otra región de su vasta obra, un endecasílabo tan atrevidamente oral como: "Pero por qué, pero por qué, Dios mío?", para remate de un elegiaco soneto de $1887.100 \mathrm{Y}$ es que en los años de $A z u l . .$. el joven Rubén Darío está muy lejos de contentarse con Hadas, Abriles $\mathrm{y}_{\mathrm{i}}$ Reinas Mab. Puede escribir versos como estos de "Aviso del porvenir" y de "Simón el Bobito":

Se hacen almas virtuosas y magnificas

de cuarenta caballos de vapor,

y lecciones se dan teórico-prácticas

para vencer a Lucifer al box...

Aquel nuestro antiguo Simón el Bobito, perito en pasteles de pollo y jamón,... Simón hoy es fama que en todo es perito... cien cosas ha hecho, mil cosas ha escrito el Excelentísimo Señor Don Simón.101

El poeta sabrá insertar de pronto, en el pasaje más delicado y terso, toques -no necesariamente cómicos- de magnífica "espontaneidad". Cómico era el final del retruécano versificado que Rubén (tendría entonces poco más de quince años) había dedicado "A Refugio":

...tú, que te llamas Refugio,

¡Refugio, refugiamé!102

Dos años antes de morir, el "amante marido" transportará el enclítico acentuado a la conclusión de unos endecasílabos maravillosos:

¿Hacia la fuente de noche y de olvido,

Francisca Sánchez, acompañamé !103

Rubén se mueve con admirable señorío por todos los planos del idioma, y lee, compara, medita sobre esos temas. No es extraño que le hagan sonreir quienes traducen su interés gramatical en discusiones de injuria y palmetazo. Véase, para ejemplo, el malicioso retrato que en El viaje a Nicaragua traza Darío de su paisano Enrique Guzmán, inconmovible purista de campanario: " $E x$ Exelente Sr. Guzmán, el mismo, invariable, incambiable desde hace treinta, cuarenta, cincuenta años: qué

100 "A Ladislao Errázuriz", en Poesias, p. 879.

101 Poesías, p. 872.

102 Poesias, p. 140.

103 "A Francisca", en Poesías, p. 1,083. 
sé yo!". 10a Por un lado, Guzmán es "el único miembro correspondiente de la Real Academia Española que haya existido en Nicaragua", 105 como que, en cosas de gramática, "ha tenido por allá, en años ya lejanos", bastante éxito; por otra parte, "el Sr. Guzmán es menos gustado en el resto de Centroamérica que en Nicaragua; y en Nicaragua, para saborearlo por completo, se necesita ser de su ciudad de Granada y, posiblemente, de su barrio". ${ }^{106}$ No nos sorprende que el ultra-localismo del purista se combine con su ultra-agresividad. Guzmán se parece un tanto -agrega Darío- a Antonio de Valbuena, el temible español, pero es un Valbuena "con más cultura, y que mezcla taimadamente a falsas inocencias de cura oblicuo desplantes y pesadeces de dómine criollo". ${ }^{107}$ Bueno es recordar que, ya en I882, el "niño prodigio de quince años" había replicado con fuerza y amplitud a los ataques pequeñistas de ese don Enrique Guzmán Rivas. ${ }^{108}$ Rubén aboga ya entonces por el liberalismo o liberalidad lingüística de "las emancipadas hijas de España" contra la tiranía de la Real Academia, "más firme i poderosa que Fernando VII".109

La ironía seguirá acudiendo con facilidad a la pluma de Darío cuando toque estas cuestiones. Graciosa, en El viajie a Nicaragua, ${ }^{110}$ su descripción de cómo "el gramaticismo y el filologismo" penetran desde Colombia y Venezuela en la América Central, como una amable epidemia o monomanía: "De ahí que todavía se encuentre quienes juzguen que el hombre ha sido creado por Dios para aprenderse el Diccionario de galicismos de Baralt y las Apuntaciones sobre el lenguaje bogotano de D. J. Rufino [sic] Cuervo". Y poco después, sin que podamos distinguir bien si a lo que se alude es al ambiente de América Central o al de toda Hispanoamérica: "Una de las razones que hicieron popular y famoso a un escritor ecuatoriano, genial, por otra parte, D. Juan Montalvo, fue su manera de escribir arcaica, su culto por Cervantes y por el Diccionario". Nótese lo medido de la afirmación: lo que Rubén señala es un motivo entre otros de la vasta reputación de Montalvo, de cuyo genio, "por otra parte", no le cabe duda. El propio Darío puede reconocer el talento de escritores hispanoamericanos que, en el extremo opuesto, cultivan la musa popular

\footnotetext{
104 El viaje... e Historia..., p. 77.

105 El viaje... e Historia..., p. 72.

106 El viaje... e Historia..., p. 77.

107 Ibidem.

108 Véase Víctor Sánchez Montencgro, "Darío, precursor de los congresos de academias...", en Noticias Culturales del Instituto Caro y Cuervo, Bogotá, no $72,1^{\circ}$ de enero de 1967 , pp. 19-22.

109 Ap. Sánchez Montenegro, p. 21 .

110 Pp. $77-78$.
} 
y rural. Nada impide al poeta de la "Sonatina" y del "Responso a Verlaine" apreciar inteligentemente al costarricense Aquileo Echeverría. Es curioso, pero de ninguna manera contradictorio, ver a Darío elogiando y transcribiendo las "concherías" y, al mismo tiempo, penetrando con vivo interés en las explicaciones linguísticas de un Roberto Brenes Mesén. Todo es útil para aquilatar mejor esa poesía alegre, honesta, sana y refrescante que Rubén contrapone a la vacuidad y ostentación de moda, "a tanta imitación desatentada, tanto pseudo modernismo, tanta farsa intelectual como los que han invadido la literatura española e hispanoamericana al amparo de la libertad del Arte y de la sinceridad y noble entusiasmo de los iniciadores."11

Si él mismo suele dar entrada en su obra a formas no generales o académicas, tan necesario es ver su papel en cada ocasión como apreciar los motivos que a menudo, en revisiones o reediciones, llevaron a sacrificar ciertos regionalismos y coloquialismos y a sustituirlos por expresiones comunes a la lengua de América y España. Así reemplaza Darío en Azul..., edición de 1905 , el chilenismo roto con una palabra más neutra, obrero - ni siquiera, como puede verse, con un estricto sinónimo-, y el nombre, demasiado local, de "Playa-Ancha" con cementerio. ${ }^{112} \mathrm{La}$ intención momentánea del escritor, su sentimiento y visión del conjunto, su busca de una caracteristica tonalidad es lo que decide en última instancia. El hacer rimar verdé con estáliz en un poema de 1906 no significa pretender que verdá sea palabra normal (ni "normal" licencia poética); no es confundir lo popular con lo académico. Acerquémonos al poema: esa rima es sólo una pirueta, que cabe muy bien en el coloquio de Darío con "la señora de Leopoldo Lugones". Monólogo en verso, donde con parecido humor se permite el poeta jugar con rimas hispanoextranjeras como: "Barcas de pescadores sobre la mar tranquila / descubro desde la terraza de mi villa (p. 750) y utilizar luego, con el mismo sentido $\mathrm{y}$, sin duda, diverso sonido, la palabra española: " $\mathrm{Y}$ hay villa de retiro espiritual famosa" (752), o hacer que, con alguna violencia, consuenen lo todavía exótico y lo ya semi-hispanizado: "y conforme el poe-

I.1 "La literatura en Centro América. El poeta de Costa Rica", en Todo al vuelo, p. 91. Echeverría había prodigado alabanzas al $A$. de. Gilbert de Darío, en La Unión de San Salvador, año $2, \mathrm{n}^{\circ} 73,4$ de febreto de $1890 ; \mathrm{cf}$. Diego Manuel Sequeira, Rubén Daria criollo en El Salvador, León, Nicaragua, 1964, pp. 138139.

112 Cf. Erwin K. Mapes, "Una edición conmemorativa de las obras de Rubén Darío publicadas en Chile". en Memoria del Primer" Congreso... de Literatura Iberoamericana, México, D. F., 1939, p. 119.

113 "Epístola a la señora de Leopoldo Lugones", en Poesias, p. 750. Véase, sobre este y otros tipos de rimas, el minucioso estudio de Tomás Navarro, "Fonología y pronunciación en las rimas de Rubén Dario", en sus Estudios de fonología 
ta, tengo un Cristo y un máuser. / Así vive este hermano triste de Gaspar Hauser" (750), o rimar "ditirambo" con el clásico Arcades ambo (747), o "Rodenbach" y "una fuga... de ¡Bach!" (747), "dé" y "el Crédit Lyonnais" (748), "Anvers" y "la terre dols forners"114 (749), "Porto-P1'" y la conjunción "Y" (75I).115 Lo que hay de travesura en ese encuentro de verdá y está salta a la vista en cuanto se le coloca en su contexto:

A veces mę dirijo al mercado, que está en la Plaza Mayor. (¿Qué Coppée! ¿no es verdá?)

$Y$ no faltan los pequeños misterios de pronunciación y grafía en escritor tan anhelante siempre de enriquecimiento y renovación. Is fácil que el joven Rubén dé cabida a formas regionales cuando escribe versos en tono alegre y familiar: "teniendo sus bartuntos bien fundados / de que la oda era buena, retebuena"; ${ }^{111}$ menos fácil, tratándose de poeta tan precozmente viajero y lector, es decidir en qué habla local piensa exactamente cuando compone este abrojo, un par de años después: "Bota, bota, bella niña, / ese precioso collar. .."117 ¿Regional o personal la pronunciación de "Yoconda" (la de Leonardo da Vinci), como escribe "fo-

española, Syracuse, 1946 , pp. 178 y sigs.

114 Corrijo foners - sin duda errata - siguiendo el texto de Méndez Plancarte, 1954, p. 852 .

İ15 O comenzar con dos versos en francés que obligan a pronunciar pintorescamente el apellido de la destinataria (746). O añadir notas al pie tan instructivas como: "He leído ya el libro que hizo Aurora Dupin./Fue Chopin el amante aquí. ¡Pobre Chopin!" (752). El tono de esta explicación no es precisamente el del admirable paréntesis de "El reino interior", en Prosas profanas, p. 603: "(Papemor: ave rara; Bulbules: ruiseñores)"; véase Arturo Marasso, Rubén Dario y suz creación poética, pp. 143 y 411 , donde se indica además como fuente del papemor el Petit glossaire... de Plowert (Paul Adam). Si es cierto, como el gran erudito piensa, que Darío pudo acaso partir, para su paréntesis en verso, de estos dos alejandrinos también parentéticos y filológicos de Pedro Antonio de Alarcón: "(Quien dice Benaldúa ha dicho 'Hija del río';/pues río es guad en árabe; el, al; e bija, ben)", resalta aun más la fluidez y gracia de la "imitación". La travesura de Rubén, como muchas otras de su prosa y verso, preludia ya, a su vez, ciertas humoradas que la poesía ulterior en lengua española desarrollará con muy distinto sentido de las proporciones. Recuérdese el juego entre texto y nota que urde José Moreno Villa en sus "Tres víctimas de la gran guerta": "La famosa doncella/del Rhin, no canta más./Huyó de Heine; en cambio/lieva un "Hut" de bazar./Prefirió a las romanzas// lunáticas, la paz/que le ofreció dichoso/un "social-democrat".//Mas todo fue al diablo./(Zum Teufel noch einmal!)/armado hasta los dientes/se han llevado a su Franz.//Nota:/"Heine", vate francófilo /y semita, además./"Der Hut", es el sombrero./"Zum Teufel noch einmal"/es una imprecación,/y "social-democrat",/es el hombre pacifico/ que se llamaba Franz" (Evoluciones, Madrid, 1918, p. 244).

116 "A Ricardo Contreras", en Poesías, p. 343.

117 En Poesías, p. 460. 
néticamente" en sus versos a una dama chilena ¿118 $^{2 A}$ qué recuerdos de tierras lejanas y a qué variados intereses de escritor apuntan sus hábitos idiomáticos, fluctuantes y complejos? Aun el Darío familiarizado con España se complacerá en giros como "Tan no es nuevo. .."119 y en palabras como pollera 'falda', 120 morocha 'morena', 121 repartición 'oficina pública'122 Darío parece estar hablando simultáneamente a sus lectores de distintos países cuando escribe de "plátanos o bananas". ${ }^{123}$ Hay que seguitlo en su cronología y en sus gustos sinuosos y renovados, y observarlo con escrupuloso sentido del contexto. Lo importante no es que en uno de sus cuentos decida utilizar el saludo rioplatense de "¡buen día!" y ponerlo en boca de un personaje, sino que la acción del cuento trascurra en Roma y en el siglo I antes de Cristo, y sea Miecenas quien salude a cietto poeta exclamando: "Buen día, Horacio!"124 Lo peculiar no es que, residiendo Darío en Chile, hable de porotos, sino que en una misma frase de "El fardo" reúna vistosamente "el grano del poroto y la sangre hirviente de la viña". ${ }^{125}$ No está de más acompañar a Rubén en su divertido desfile de hortalizas cuando describe una exposición parisiense de Arboricultura y Horticultura, pero interesa en especial su enumeración golosa y artística, informativa y burlesca, de patatas —no papas-, desde la "patatita mignonne, flor de Parmentier", hasta la patata enorme... que el pre-naturista Bernardino [es decir, Bernardin de Saint-Pierre] habría creído hecha ex profeso por la buena Divinidad para ser comida en familia", como interesa verlo detenerse en los zapallos, "que obligan a la veneración con sus inmensas panzas monacales". ${ }^{126} \mathrm{Ni}$ el tratado de botánica ni el diccionario de americanismos bastarán para hacer justicia a esta ágil y continua invención.

ل118 "Dama", en Poesias, p. 1,090. Pero "Gioconda" en p. 976 ("Toast" a Eduardo Schiaffino), en "La sonrisa", Poemas en prosa, p. 209, y en "Impresiones de Salón", Parisiana, p. 196.

119 "La evolución del rastacuerismo", en Opiniones, p. 138.

"200 "Palomas blancas y garzas morenas", en Cuentos completos, p. 87.

121 "Porteña", en Poesias, p. 964. Y presentando a los porteños su "Sinfonía en gris, mayor" (Ĺa Tribuna, 8 de enero de 1894), Rubén explica que la escribió "en un país de tierra caliente, donde las morochas abundan" (Escritos inéditos, p. 34 ).

Iæ2 "AA poblá...", en Cuentos completos, p. 314. Otros ejemplos en Letras bispánicas, p. 243. No pocas veces utiliza Rubén atorrante (un ejemplo, en "Notas teatrales", España contemporánea, p. 42); por otra parte acude a compadrito para explicar qué es el chulo madrileño ("Cyrano en casa de Lope", España contemporaned, p. 46).

123 Autobiografia, p. 12.

124. "Respecto a Horacio", en Cuentos completos, p. 219.

125 Cuentos completos, p. 30.

126 Peregrinaciones, Madrid, 1918 , pp. 25-26. Pero, un par de renglones después de los zapallos: ". . . una cantidad de las más variadas legumbres, desde las majestuosas calabazas hasta las finas arvejas"' (los subrayados son mios). 
Asi brotan a cada paso sus originales derivados, palabras compuestas, neologismos, que merecerían por sí un minucioso estudio. Cuando, en el poema a la muerte de Ganivet, 127 Rubén prefiere decir ascendimiento (anunciado en el verso anterior por ascendió) y no ascenso ni ascensión, no es ese un mero capricho morfológico. La palabra escogida por el posta forma, implícitamente, pareja ideal con el consagrado descendimiento, y entra con razonable coherencia en todo un grupo de derivados que Darío utiliza sin miedo a la tradición ni al diccionario. El poeta, dirigiéndose a Ganivet, imagina la escena del suicidio:

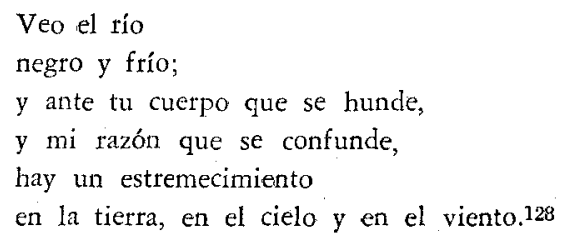

$Y$ el final del poema alza estelarmente el espíritu de Ganivet, desde el Dvina hasta el cielo:

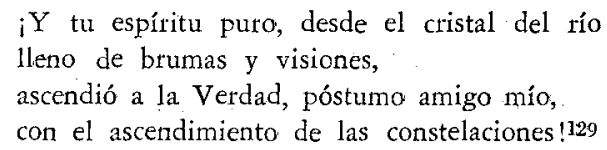

Esperariamos la palabra aparición, en La caravana pasa, cuando, refiriéndose Rubén a Ángel de Estrada y a su libro El color y la piedra, nos dice que "tanta agitación causó con su aparecimiento en Buenos Aires"; 130 quizá el deseo de evitar la rima llevó al escritor a reemplazar directamente el segundo -ción, sin perder demasiado tiempo en buscar un sinónimo de agitación, pero no es muy probable que tales motivos le hicieran preferir esa forma en su cuento "D. Q.": "un aire que refrescó el campo todo sopló del lado de la aurora, y ésta inició su aparecimiento". .11 $^{131}$

1227 Poesías, pp. 1,009-1,011. Me atengo a ese texto de A. Oliver Belmás (que corresponde al de la ed. Méndez Plancarte, 1954, pp. 1,129-1,131), no obstante la enmienda propuesta en la "Nota preliminar...", pp. xii-xiv.

128 Poesias, p. 1,010.

129 Poesias, p. 1,011 .

130 P. 177. Con la misma acepción, en El Tiempo de Buenos Aires, 18 de enero de 1898: "aparecimiento de la Revista de América" ("Rethoré", en Escritos inéditos, pp. 159-160).

131 En la citada Gareta del Fondo de Cultura, p. 8. Así también al referirse Darío al entierro de Larra. "con la nota saliente del aparecimiento de Zorrilla" ("Una novela de Galdós", en España contemporáned, p. 239), o al funesto pesi- 
Floración, escribe Dario traduciendo del francés, ${ }^{132}$ pero por cuenta propia, pintando el mar en un artículo de 1892 , habla de él como de un "mar de pizarra, con una multitud de florecimientos de nieve". ${ }^{133}$ Si los sustantivos en -miento no abundan en español moderno tanto como Darío quisiera, los repone con toda libertad: "el conseguimiento del éxito", 134 "el despertamiento florestal" (esto es, el despertar del bosque).135. Añádase rompimientos, con ostensible ampliación del área semántica habitual (rompimiento de una amistad, de un noviazgo); describiendo uno de sus espectáculos predilectos - la caída de la tarde sobre el horizonte marino-: "cien triunfos de color, y cien rompimientos, y cien aguas de perla, de metal, de pedrería", ${ }^{136}$ y en el mismo libro, pocas páginas después: "sus rompimientos de oro y de piedras preciosas". 137

En este viviente calidoscopio, inquieto y expresivo, el más leve estímulo - hispánico o forastero- pone en movimiento la invención verbal. Rubén prodiga sustantivos como diplomata y bedekerismo, 138 como tartarinismo ${ }^{139}$ y politiquista, ${ }^{140}$ como el muchacbicidio de la temprana epístola "A Ricardo Contreras"141 (recuérdese el ya citado, y muy posterior, bipopotamicida). Enuncia y conjuga verbos como parisienizar, 142 zorrillizar, ${ }^{143}$ ronsardizar, 144 lelianizar145 (por 'verlainizar'), peladanizar, ${ }^{146}$ pigmalionizar, ${ }^{147}$ nemrodizdr ('cazar'). ${ }^{148}$ No le basta, con minúscula, cri--

mismo de ciertos españoles y el "aparecimiento de los profetas del mal" ("Barcelona", en Tierras solares, p. 852).

132 "La vida de Verlaine. Realidad y leyenda", en Todo al vuelo, p. 198. También en "Nuevos poetas de España", Opiniones, p. 202.

133 "En el mar", en Diario de Centro-América, Guatemala, 31 de mayo de 1892, y en Diego Manuel Sequeira, Rubén Dario criallo en El Salvador, Nicaragua, 1965 , p. 417.

134 "El Provincianito", p. 40.

135 "Naturaleza tropical", en Poemas en prosa, p. 133. Cf. el "despertamien.

to" de España, en Tierras solares, p. 853.

136 " "Los caprichos del sol", en Poemas en prosa, p. 99.

137. "Monotonía del mar", en Poemas en prosa, p. 103.

138 "Balada a Leopoldo Díaz", en Poesías, p. 990; "Letras dominicanas", en Letras, p. 67.

139 "Granada", en Tierras solares, p. 905.

140 "Barcelona", en Tierras solares, p. 852.

141 En Poesia, p. 335. Cf. la Palas Athenea "Gorgonicida", de Poesías, p. 1,129, y el Vacher "pastoricida" -asesino de pastores- de Impresiones, $y$. sensaciones, Madtid, 1925, p. 31.

142 "Málaga", en Tierras solares, p. 870.

143 "De Val", en Todo al vuelo, p. 47.

144 "A propósito de Mme. de Noailles", en Opiniones, p. 84.

145 Ibidem.

146 "Marinetti y el futurismo", en Letras, Madrid, 1918, p. 192.

147 "José Entique :Rodó", en Prosa dispersa, p. 162.

148 Autobiografía, p. 154. 
sástomo: necesita crisostómico, ${ }^{149}$ "cátedras. . . más o menos sorbónicas", 150 "císnico plumón", ${ }^{151}$ "caja pandórica", 152 "vastas tazas demetéricas"; 153 un León XIII a quien los pintores prestan rasgos de "águila jupiterina, que es también pátmica"; 154 tres poetas griegos que convergen en cierto nombre de mujer, "nombre anacreóntico, biónico y moscoico". 155 No sólo buyente, sino baritonante, 156 no sólo danaideano, 157 sino besperidino (como del Jardín de las Hespérides), ${ }^{158}$ y orgías de adjetivos en esco: "noche barriolatinesca", "tipos luiscatorcescos", "militarismo montjuichesco". is9 $\mathrm{Y}$ las fuertes sorpresas de lo sencillo e inesperado: las "escalas firmamentales" construidas por la luz mágica del crepúsculo, ${ }^{160}$ " "los tiempos terribles en que cayó, rojamente, el pobre y grande conservador don Antonio Cánovas". 161

No necesitaba Rubén acudir a moldes llamativamente nuevos para hacer vibrar la página con acentos nunca oídos. Dos poesías suyas se llaman "Recreaciones arqueológicas", 162 y en una de ellas _ "Friso" - los endecasílabos suenan levemente a los de Moratín, y más a los de Menéndez y Pelayo; pero en esos rotundos versos sueltos entran, no leves sino muy a fondo, notas atrevidamente modernas. Si Rubén utiliza los modelos del antiguo cancionero español y se complace en evocar loores, layes, decires y esparzas, finidas y tornadas, ${ }^{163}$ lo sorprendente es el despliegue de flamantes elegancias eróticas que él infunde en los viejos esquemas ("expreso amores nuevos", ha aclarado el poeta), ${ }^{164}$ y decisiva la aleación de lo uno con lo otro. Si el lector tropieza con sonoros indigenismos, lo significativo es, sobre todo, la oportunidad y gracia de su combinación con muchos otros recursos. Tal o cual forma coloquial hispano-

149 "Cátedra y tribuna", en Escritos inéditos, p. 5; "Castelar", en Cabezas, p. 140. Cf., para el sustantivo crisóstomo, "Un sermón", en Cuentos completos, p. 179, también a propósito de Castelar: "este admirable chrysóstomo".

150 "Dilucidaciones", en Poesías, p. 700.

151 "El poeta León XIII", en Opiniones, p. 44.

152 "Salutación del optimista", Cantos de vida y esperanza, en Poesías, p. 631.

153 El viaje... e Historia..., p. 2.

li54 "El poeta León XIII", p. 38.

155 "Menéndez y Pelayo, I", en Escritos inéditos, pp. 85-86.

156 "En Chile", Cuentos completos, p. $50 ;$ El viaje... e Historia. . . p. 204.

157 "En el Gran Palacio", Peregrinaciones; p. 39.

1158 "Eduardo Dubus", en Los Raros, p. 154.

159 Autobiografía, p. 117 (y "La vida de Verlaine...", en Todo al vuelo, p. 199; en "Madrid", España contemporánea, p. 28, llega hasta "reuniones semibarriolatinescas de Fornos"); "La labor de Vittorio Pica", en Impresiones $y$ sensaciones, p. 61; "Barcelona", en Tierras" solares, p. 853.

160 "Los caprichos del sol", Poemas en prosa, p. 99.

161. "Barcelona", en Tiestras solares, p. 853.

162 prosas profanas, en Poesias, pp. $597-602$.

163 Prosas profanias, en Poesías, pp. 608-614:

164 Viaje... e Historia..., p. 196. 
americana - lo hemos visto- puede llamarnos la atención en el verso - la prosa de Rubén, pero el cbe deja de ser una mera y aislada curiosidad rioplatense cuando, llegada la ocasión, se mezcla sabiamente con otras "curiosidades" en un alarde de puntillismo audaz y cosmopolita: "Suena un che o un all right, un ja o un kalimera".165

Nada es demasiado simple en Rubén. Su galicismo, evidente y múl. tiple, no es simple galicismo. Trastornar gloriosamente el equilibrio idiomático anterior haciendo afluir a una ancha tradición hispánica esencias espirituales y verbales, "no sólo de las rosas de París"166 sino de todas partes, ni fue programa sencillo ni pudo lograrse con una sistemática y tozuda obediencia a programa alguno. Lejos de Rubén (que se consideraba a sí mismo "el ser menos pedagógico de la tierra") 167 la idea de codificar su labor y sus ideales literarios en trasmisibles recetas técnicas de cosmopolitismo. $\mathrm{Ni}$ es elemental y de una pieza su amor a lo castizo ni su entrega a la obra -obras son amores- de hacer revivir el tronco de la lengua literaria española. Gran modelo de amor en obra. Gran dechado, para América y España, de casticismo original en un poeta originalísimo. Casticismo, pues - si cabe parodiar aquí las "Palabras liminares" del propio Darío-, que es sólo suyo, y en él.

\section{Harvard University}

\section{RAIMUNDO LIDA}

165 "En el Luxembourg", en Poesias, p. 1,019. Este "Luxembourg" francés, desde el título, ayuda a evitar el equívoco con el Ducado homónimo y prenuncia ya el múltiple exotismo del conjunto, en que lo parisiense es a la vez internacional o, mejor, supranacional: perfecto "rincón de ensueños" y "jardín divino" (p. 1,018). Tema grato al poeta, e insistente en el talentosísimo periodista.

166 Viaje... e Historia..., p. 189. Sobre lo deliberado de estas adaptaciones, véase Juan López-Morillas, "El Azul de Rubén Darío. ¿Galicismo mental o lingüistico?", en Revista Hispanica Moderna, New York-Buenos Aires, año 10, 1944, pp. $9-14$

167 "Dilucidaciones", en Paesias, p. 695; comp. el breve prólogo de Opiniones, 6 . 